\title{
Dialysis Prescription: A Modifiable Risk Factor for Chronic Kidney Disease Patients
}

\author{
Bernard Canaud $^{\mathrm{a}, \mathrm{b}}$ Peter Wabel ${ }^{\mathrm{c}}$ Ciro Tetta ${ }^{\mathrm{c}}$ \\ ${ }^{a}$ Nephrology, Dialysis and Intensive Care Unit, and b Aider and IRFD, Lapeyronie University Hospital, \\ CHU Montpellier, Montpellier, France; ' Fresenius Medical Care, Research and Development Intl., \\ Bad Homburg, Germany
}

\section{Key Words}

Dialysis prescription $\cdot$ Mortality $\cdot$ Dialysis adequacy

\begin{abstract}
Recent surveys of hemodialysis studies strongly support the fact that dialysis prescription is a modifiable risk factor. Six tracks to improve dialysis patient outcomes have been identified: change in vascular access option strategy and restricting catheter use; increasing time or frequency of dialysis sessions; assessment and management of fluid status; favoring removal of middle and large molecules by high-flux and convective clearance; considering ultrapurity of dialysis fluid purity as a new standard and a part of hemodialysis biocompatibility, and improving quality care and patient follow-up. By modifying dialysis prescription and by implementing a continuous quality assurance program it appears possible to improve dialysis patient survival.
\end{abstract}

Copyright $\odot 2010$ S. Karger AG, Basel

\section{Introduction}

Despite significant improvements in the management of hemodialysis (HD) patients due to a better understanding of uremia toxicity, improvements in dialysis technology, better correction of anemia and metabolic abnormalities, as well as implementation of best practice guidelines, it is quite frustrating to note that no significant improvement has been achieved in patient survival over the last decade [1]. The mortality of chronic kidney disease (CKD) HD patients remains high while wide variations across countries are observed [2]. The crude annual mortality of HD patients ranges from $6.6 \%$ in Japan to $21.7 \%$ in North America and averages 15.6\% in Europe [3]. Several factors contributing to explain such differences have been identified, schematically they belong to 2 categories: the first one includes factors that are not modifiable, such as age, sex, ethnicity, diabetes and comorbid conditions; the second category comprises factors that are modifiable, such as hypertension, uremia, anemia, dyslipidemia and inflammation. In addition, recent studies have shown that practice patterns may have a major impact on the mortality and morbidity of dialysis patients. Accordingly, these facts suggest that dialysis treatment prescription and clinical attention paid to patient care should be considered as a first-line and major modifiable risk factor. This review summarizes recent findings proving that dialysis prescription alteration may be associated with significant reduction in the morbidity and mortality of dialysis patients. The beneficial role of adjunctive therapy such as erythropoeitic stimulating fac-

\section{KARGER}

Fax +4161306 1234 E-Mail karger@karger.ch www.karger.com
(C) 2010 S. Karger AG, Basel

0253-5068/10/0294-0366 \$26.00/0

Accessible online at:

www.karger.com/bpu
Prof. B. Canaud

Nephrology, Dialysis and Intensive Care Unit

Lapeyronie University Hospital, CHU Montpellier

371, Avenue du Doyen G. Giraud, FR-34295 Montpellier Cedex 5 (France)

Tel. +33 4673384 95, Fax +33 4676037 83, E-Mail b-canaud@ chu-montpellier.fr 
tors, statins, vitamin D supplementation or phosphate binders will not be covered by this review. In other words, our objective here is to show that by modifying dialysis prescription and practice patterns, and by implementing a quality assurance program, significant improvement in patient survival might be achieved.

In this field, 6 tracks of improvement for dialysis patient care are clearly identified in the recent literature. They include the change in vascular access option strategies, the increase in the time or frequency of dialysis sessions, the assessment and management of optimal weight and fluid status, the enhancement of middle-molecule uremic toxins, the prevention of subclinical chronic inflammation and the improvement in global patient care.

\section{Changing Vascular Access Option Strategy}

Vascular access contributes highly to the morbidity and mortality of HD patients $[1,4,5]$. Changing vascular access creation and management are practice patterns that may significantly reduce the relative risk of death in HD patients [6]. Worldwide best practice guidelines are recommending early creation and first use of native autologous fistula (AVF) for HD patients [7]. This is a firstline approach that has been proved to be very efficient in reducing vascular-access-related morbidity. In case of multiple AVF failure, vascular access alternatives including PTFE graft or central venous catheter (CVC) might be envisaged [8]. However, it must be considered that PTFE graft has a high failure rate requiring frequent revision to maintain potency on mid term. Long-term tunneled CVC use is associated with a 5-7 times higher infectious risk and their use should be restricted to rescuing situations or specified indications. Moreover, CVC always bears the risk of host vein stenosis compromising further construction of arteriovenous access [9]. Timely referral of CKD patients to nephrologists and surgeons to create native AVFs should be considered as the best medical practice as soon as advanced CKD has been recognized. Adequate mapping of the arm and forearm vascular network (venous and arterial) by imaging methods (ultrasonography, phlebography) is highly suitable for guiding vascular surgery [10]. In any case, refraining from using CVC as long-term vascular access is highly desirable to reduce catheter-related morbidity [8]. Specific expertise of surgeons or nephrologists dedicated to CKD patient care is suitable to enhance both the success rate of construction and outcomes of AVF [11]. The international Dialysis Outcomes and Practice Patterns Study
(DOPPS) has shown that the use of CVC was associated with an increased risk of AVF failure and subsequently a higher mortality risk [12]. In this study, starting dialysis with a CVC was related to an increased relative risk of mortality up to $30 \%$. It must be noted, however, that this figure may be significantly altered by CVC type and practice patterns of the dialysis unit [13]. It has been reported that applying strict hygienic rules for CVC handling and filling catheters with a dual antiseptic-antithrombotic locking solution, the incidence of catheter-related infection might be minimized [14-16]. Interestingly, CVCs are now easily used as permanent vascular access in elderly subjects or CKD patients presenting with exhausted vascular access site or limited time expectancy [17].

From a clinical perspective, it is recommended to construct an autologous AVF early on, to guide vascular surgery for site of implantation and type of VA by noninvasive imaging technique. CVC should be restricted to vascular access rescuing situations and specific recommendations should be applied for catheter handling.

\section{Increasing Time and/or Frequency of Dialysis Sessions}

Treatment schedule prescription is a critical factor for dialysis efficacy and tolerance of dialysis. Due to logistical aspects, economical constraints and patient requests, shortening of dialysis sessions has been commonly applied worldwide. Faced with this therapeutic challenge, enhancement of instantaneous solute fluxes by increasing flow rates and using high-performance hemodialyzers has been a generalized trend of dialysis prescription. From a physiologic perspective, it is, however, surprising to note that the continuous rush after technical improvements has completely blunted the role of patient/HD interaction as the main limiting factor for clearance and tolerance. One must bear in mind that for a given solute the body clearance is not equivalent to the hemodialyzer clearance. Nephrologists have forgotten that the main barrier to HD efficacy and tolerance was the patient itself due to its complex body composition and to limitation of the hemodynamic adaptation.

Dialysis efficacy relies on solute mass balance (removal and load) achieved during the dialysis session with the ultimate objective of periodically restoring the patient's homeostasis. 'Dialysis dose' defined as the net product 'solute clearance' $(\mathrm{K})$ and 'treatment time' $(\mathrm{t})$, is a convenient index for assessing treatment efficacy. Gotch [18] 
developed the concept of dialysis quantification based on urea to evaluate the dialysis dose delivered to patients and to assess its impact on the outcomes. Despite its limitations the dialysis dose, referring to urea $\mathrm{Kt} / \mathrm{V}$, is a worldwide tool used to assess dialysis efficacy in practice [19]. It has been proposed to overcome Kt/V pitfalls by implementing online direct quantification biosensors on dialysis machines [20]. From a clinical perspective, it is important to underline the fact that in this equation $\mathrm{K}$ and $\mathrm{t}$ parameters have clearly not the same predictive value for $\mathrm{CKD}$ patients. In other words, increasing $\mathrm{K}$ while reducing $\mathrm{t}$ to maintain constant $\mathrm{Kt} / \mathrm{V}$ has not the same clinical impact on morbidity and mortality. Duration of dialysis (t) appears to be a stronger clinical determinant than $\mathrm{K}$ and should always be privileged when targeting high $\mathrm{Kt} / \mathrm{V}$. It is noteworthy that the Hemodialysis (HEMO) study was not able to confirm the hypothesis that high dialysis dose was superior to low dialysis dose to reduce patient mortality. In brief, this study tends to prove that HD patients' mortality does not depend on small molecule clearance provided a threshold minimum dialysis dose $(\mathrm{Kt} / \mathrm{V} \approx 1.3)$ is delivered [21]. In addition, a post-hoc analysis of the HEMO study in subgroups of patients has shown that the long-term use of high-flux membranes lowers the serum $\beta 2$-microglobulin concentration and reduces HD patient mortality [22]. Recently, the Membrane Permeability Outcome study has shown in incident dialysis patients that high-flux dialyzers were beneficial for subgroups of high-risk patients, namely diabetics and hypoalbuminemic patients [23]. By applying kinetic modeling analysis to middle-molecule solutes (inorganic phosphate, $\beta 2$-microglobulin, ...) it has been proved that removal limitation of these compounds was mainly due to their high intracorporeal mass transfer resistance [24, 25]. In other words, optimizing middle-molecule removal by dialysis requires both enhanced convective clearances using highly permeable membranes and extended treatment time and/or increased session treatment frequency to match hemodialyzer and body clearance.

Dialysis tolerance refers mainly to hemodynamic stability during the dialysis session (crash hypotensive episodes) and during the interdialytic period (hypotension, fatigue). On the one hand, clinical tolerance of dialysis session depends on the ultrafiltration rate (extracellular fluid removal) applied during the dialysis session and, on the other hand, on the patient's hemodynamic response that includes vascular refilling rate, peripheral vascular resistance adaptation and cardiac output increase. Optimized ultrafiltration rate by customizing HD treatment schedule (longer treatment time, adjunct isolated ultra- filtration), as well as reducing interdialytic weight gain by dietary counseling and salt intake restriction are very simple and efficient prescriptions to correct fluid overload and improve hemodynamic tolerance [26, 27]. Preserving the residual renal function by using biocompatible material and ultrapure dialysis fluid is regularly advocated as an additional means to restore extracellular volume equilibrium in HD patients but convincing evidence is missing [28]. Nowadays, extending dialysis duration and increasing session frequency appears to be an easy and physiological approach to improve vascular stability, to preserve quality of life and to reduce left ventricular hypertrophy [29]. This simple approach, which consists in customizing the treatment schedule to the patient's needs, is, however, challenged by patients and nurses for personal convenience and logistical consideration. Two recent studies have shown that longer treatment time was beneficial for patient survival. In the DOPPS, longer treatment time by reducing ultrafiltration rate and minimizing hypotensive episodes is associated with a reduced mortality in HD patients independently of dialysis dose [30]. Interestingly, by increasing the treatment time by $30 \mathrm{~min}$, the relative risk of mortality was reduced by $7 \%$. In the Australia New Zealand data registry study it has also been shown that longer treatment time was associated with better survival expectancy [31]. In this study, a treatment time of $4.5-4.9 \mathrm{~h}$ was associated with $20 \%$ reduction risk of death independently of dialysis dose. Such impressive results on HD patient survival might be related to the decrease of the ultrafiltration rate, the reduction in hypotension episodes, the better control of extracellular fluid volume and the higher dialysis dose delivered [32].

From this section one should consider as a new standard in HD that a minimal treatment time of $270 \mathrm{~min}$ $(4.5 \mathrm{~h})$ should be delivered and a maximal ultrafiltration rate of $10 \mathrm{ml} / \mathrm{h} / \mathrm{kg}$ should be applied for patients treated on a thrice weekly schedule.

\section{The Assessment and Management of Fluid Status}

The HEMO study has estimated that $72 \%$ of the chronic HD patients exhibit hypertension despite intervention with antihypertensive medication [33]. Severe fluid overload has been found to be present in $25 \%$ of the chronic HD patients in Europe, even though it is likely that this excess fluid could be removed with ultrafiltration [34]. Hypertension and fluid overload play a major role in the development of left ventricular hypertrophy, which is 
known to be highly prevalent in the HD population [35], and studies have attributed significant numbers of deaths to left ventricular hypertrophy $[36,37]$. The management of hypertension and fluid overload remains an ongoing challenge in many patients, but where improvements in the treatment strategy have been effective, left ventricular hypertrophy appears not to be an irresolvable problem [38-40].

One reason why a better outcome is difficult to achieve is that the tools for the assessment of major cardiovascular risk factors such as fluid overload are not sufficiently adequate [41]. Blood pressure is used universally as a clinical indicator of excess fluid in the assessment of chronic HD patients [42], but it has severe limitations. While some forms of hypertension are undoubtedly the consequence of fluid overload, several studies have shown that there are many patients where such a relationship does not hold true [43-47]. Several reasons could explain this contrariness of findings: cardiac insufficiency $[48,49]$ or antihypertensive medication could blunt the sensitivity of blood pressure as a reliable marker of fluid status [43] or other factors besides fluid overload that influence the blood pressure [38]. As the interpretation of blood pressure can be problematic, better ways to obtain objective measurement of fluid status have long been sought. Unfortunately, of the methods available, some are indirect while others are too subjective, and without exception it is difficult to define clinically relevant endpoints [50-53]. However, advances in body composition analysis technology $[54,55]$ have led to the development of a new device (body composition monitor) that allows objective and quantitative measurement of fluid overload for the first time. It has been demonstrated that the sensitivity and specificity of this method are superior to established clinical methods [56]. The output parameters of this device have been validated extensively in both healthy subjects and dialysis patients [57]. Since the advent of the body composition monitor, a number of interesting findings have been reported. Of a representative cross-section of 500 chronic HD patients in Europe, 25\% revealed severe fluid overload [52]. The long-term impact of severe fluid overload and mortality over a 3.5-year follow-up has been studied [58]. The results of this study indicated a significantly increased risk of mortality (hazard ratio = 2.1) for patients in whom the pretreatment fluid overload exceeded 2.5 liters.

Is it possible to transfer the objective assessment of the fluid status into an adjusted dialysis prescription with the target to modify the risk factor of fluid overload?

Dialysis Prescription: A Modifiable Risk

Factor for CKD Patients
In a recent prospective trial, normohydration weight calculated as the difference between the pretreatment weight and the fluid overload was used in the dialysis prescription [59]. Through use of this modified prescription, the fluid status of the overloaded patients (fluid overload $>2.5$ liters) was reduced by an average of 2 liters over a longer time period. In these patients the systolic blood pressure was lowered significantly by $25 \mathrm{~mm} \mathrm{Hg}$ despite reductions in antihypertensive medication. Additionally the ejection fraction improved. Intradialytic adverse events remained low and unchanged in frequency.

\section{Favoring Removal of Middle- and Large-Molecule Uremic Toxins}

The toxic role of middle molecules has been regularly advocated for $>30$ years in the uremic syndrome to explain the severity of CKD. The middle-molecule hypothesis has clearly stimulated clinical research and promoted the development of highly permeable membrane and convective treatment modalities. Unfortunately, clinical research in this field has remained relatively disappointing since no strong and predictive marker of middle molecules has emerged. The lack of middle molecule biomarker may explain why the Kt/V urea has been extensively used despite its poor predictive value. Time has changed and recent experimental data gathered by the Eutox group has revived the interest in middle-molecule toxicity [60]. The vascular endothelium appears to be a privileged target for these compounds contributing to promoting and accelerating atherosclerosis and vascular calcification processes [61].

Interestingly, 2 compounds, inorganic phosphates $\left(\mathrm{PO}_{4}\right)$ and $\beta 2$-microglobulin, might be considered as good surrogate markers of this category of toxins, both of them being characterized by their clinical relevance and their high intracorporeal mass transfer resistance. Inorganic phosphates have a small molecular weight (33 Da) and by definition do not belong to the middle-molecule group. Indeed due to their physical properties (hydration, polarity) phosphates mimic middle-molecule kinetics in the dialysis patient. Optimal correction of inorganic phosphate concentration is of critical importance in dialysis patients. By promoting passive and active vascular calcification, hyperphosphatemia is a well-recognized factor implicated in the cardiovascular risk of CKD patients. Adequate control of hyperphosphatemia, a primary target of dialysis adequacy, is rarely achieved. In the DOPPS $52 \%$ of the HD patients are above the phosphate

Blood Purif 2010;29:366-374 369 
recommendation of the Kidney Disease Outcomes Quality Index despite the extensive use of phosphate binders [62]. Better control of hyperphosphatemia by dialysis is achievable provided the dialysis treatment strategy is revised and mass transfer is increased. Enhancing phosphate removal by dialysis requires first to increase instantaneous phosphate clearance (high flux and convective flux) and second to enhance the duration (or frequency) of treatment time. Until recently, $\beta 2$-microglobulin toxicity was mainly associated with the risk of developing $\beta 2$-microglobulin amyloidosis in long-term dialysis patients. Serum $\beta 2$-microglobulin concentration is now strongly associated with mortality risk in dialysis patients. Post-hoc analysis of the HEMO study has shown that increased $\beta 2$-microglobulin concentrations above a threshold value of $27 \mathrm{mg} / \mathrm{l}$ are predictive of an increased risk of death in HD patients [63]. $\beta 2$-Microglobulin concentrations between 42 and $50 \mathrm{mg} / \mathrm{l}$ are associated with $60 \%$ higher mortality risk. $\beta 2$-Microglobulin should be considered as a useful and predictive biomarker of mortality and infectious risk in HD patients [64]. For this reason the $\beta 2$-microglobulin concentrations should be considered as quite interesting a marker of dialysis efficacy. The interest in $\beta 2$-microglobulin may be due to its dual significance; on the one hand, it is a surrogate for middle-molecule dialysis dose, and on the other, it is a bioincompatibility marker for the dialysis system [65]. Albumin-bound toxins represent another category of uremic compounds that have been associated with dialysis patient mortality. Paracresol or paracresyl sulfate and indoxyl sulfate are the most leading compounds that are implicated in the endothelial dysfunction. Increasing removal of these compounds thus appears highly desirable. Due to the complexity of their structures and kinetics, removal of these compounds by dialysis is still a challenging concern. Two therapeutic modalities are currently proposed, one consists in using albumin-leaking membranes and the other in increasing convective clearance. Recent studies based on highly efficient convective modalities (HDF) have confirmed that low paracresol concentrations were associated with a significant reduction in dialysis patient mortality [66].

The beneficial role of high-flux membrane in patient mortality is strongly supported by recent studies. Two cohort studies have recently shown that regular use of highflux dialysis membranes was associated with a significant reduction in HD patients' mortality $[67,68]$. In a post-hoc analysis of the HEMO study it has been shown that patients exposed to high-flux membranes for $\geq 3.7$ years were associated with reduced mortality and cardiovascu- lar risks [69]. Interestingly, this effect was independent of the urea $\mathrm{Kt} / \mathrm{V}$ delivered but was related to the $\beta 2$-microglobulin concentrations. In the Membrane Permeability Outcome study, a prospective randomized trial in incident dialysis patients, assessing the effect of membrane permeability flux on mortality, the use of high-flux membranes in 2 subgroups of patients, diabetics and hypoalbuminemics, is also associated with a better survival [23].

The beneficial influence of enhancing convective clearances with high-flux membranes on patient survival has also been reported in several studies. The DOPPS conducted in Europe identified that the subgroup of patients receiving HDF treatment had a reduced gross mortality risk [70]. This beneficial effect has been confirmed in a multivariate analysis including age, 14 comorbidities and dialysis dose. The volume of fluid exchanged per session (liters per session) is an interesting surrogate of the convective dialysis dose delivered. In this case mortality was reduced by $7 \%$ in the low-efficiency group (7-15 liters) and 35\% in the group of patients receiving high-efficiency HDF (15-25 liters). This is the first study showing that better survival was associated with increased convective dialysis dose. A recent prospective study conducted in prevalent dialysis patients has also observed a significant survival improvement after 30 months of treatment by hemodiafiltration [71]. Three prospective randomized European studies are currently running to evaluate the precise effect of HDF on the mortality of dialysis patients with a particular focus on cardiovascular events [72].

All these facts support a pathogenic role of middle molecules in mortality of HD patients. Inorganic phosphate and $\beta 2$-microglobulin represent 2 middle-molecule compounds that should be incorporated in the biomarker panel serving to evaluate dialysis adequacy. The time has come to increase the solute convective clearance and to define a new standard for dialysis dose efficacy including blood $\beta 2$-microglobulin concentrations [73].

\section{Implementing Ultrapurity of Dialysis Fluid as New Standard of HD System}

Ultrapurity of dialysis fluid standing for sterile and nonpyrogenic solution has been proposed to reduce microbial-contamination-related problems in $\mathrm{HD}$ and to facilitate the development of online hemodiafiltration methods [74-76]. The regular use of ultrapure dialysis fluid has several beneficial effects: it amplifies the beneficial role of biocompatible synthetic membrane in pre- 
venting activation of circulating cells and proteins, it prevents monocyte activation and proinflammatory cytokine release, and it reduces polymorphonuclear cell burst preventing release of reactive oxygen species and minimizing oxidative stress [77]. Ultrapure dialysis fluid is newly proposed as standard for contemporary renal replacement therapies that is recommended by international guidelines to globally improve the hemocompatibility profile of the dialysis system and to minimize patient/ HD interaction. A highly biocompatible dialysis system is desirable to prevent chronic inflammation and its harmful consequences in long-term dialysis patients [78]. This aim appears of crucial importance to prevent the development of dialysis-related complications including malnutrition, atherosclerosis and anemia. This fact is strongly supported by a recent mid-term prospective study showing that the reduced inflammatory profile of dialysis patients was associated with a noteworthy reduction in cardiovascular events and an improvement of patient survival [73].

\section{Improving Practice Patterns and Dialysis Patient Supervision}

Practice patterns may affect dialysis patient outcomes. This is quite original and clear-cut an observation that has been made by the DOPPS. The DOPPS is an international prospective observational study conducted worldwide in HD patients that evaluates several dimensions of practice patterns in dialysis facilities and analyzes consequences on patient outcomes. Several observations made by the DOPPS support the fact that quality care is a major determinant of patient outcomes. Physician time spent looking after patients (physician/patient time contact), number and qualification of nursing staff (patient/staff ratio), drug prescription, dialysis adequacy targets and vascular access management are among the more power- ful and significant findings associated with better patient survival. The DOPPS findings also substantiate the fact that dialysis prescription and effective dialysis delivery are major factors for improving dialysis patient outcomes. Based on 6 targets of dialysis care, dialysis dose $(\mathrm{Kt} / \mathrm{V}$ $\geq 1.2$ ), anemia $(\mathrm{Hb}>110 \mathrm{~g} / \mathrm{l})$, serum phosphorus $\left(\mathrm{PO}_{4}\right.$ $<1.70 \mathrm{~mm} / \mathrm{l})$, serum calcium $(>2.40 \mathrm{~mm} / \mathrm{l})$, albumin $(>35$ $\mathrm{g} / \mathrm{l})$ and catheter use $(<7 \%)$, the DOPPS has estimated that a substantial number of patient life years could potentially be saved if every chronic HD patient who is currently outside of the specified target was able to achieve these objectives partly (50\%) or totally (100\%) [79].

From a clinical perspective, it is then recommended to improve patient care by implementing guidelines and ensuring quality assurance processes in each dialysis facility. Selecting simple pertinent indicators of dialysis efficacy, focusing on patients outside guidelines and correcting causes of excursion would significantly improve the patient dialysis survival rate [80].

\section{Conclusion}

This review shows that large opportunities exist to improve dialysis patients' care and outcomes. Recent clinical study findings have clearly indicated that dialysis prescription is a modifiable risk factor. Among them, 6 tracks to improve dialysis patient outcomes have been identified; they include: changing vascular access option strategy and restricting catheter use; increasing time or frequency of dialysis sessions; assessment and management of fluid status; favoring removal of middle and large molecules; incorporating dialysis fluid purity in the global biocompatible concept, and improving quality care and patient follow-up. In other words, by modifying dialysis prescription and by implementing a continuous quality assurance program, it is possible to improve dialysis patient survival.

\section{References}

1 Rayner HC, Pisoni RL, Bommer J, Canaud B, Hecking E, Locatelli F, Piera L, Bragg-Gresham JL, Feldman HI, Goodkin DA, Gillespie B, Wolfe RA, Held PJ, Port FK: Mortality and hospitalization in haemodialysis patients in five European countries: results from the Dialysis Outcomes and Practice Patterns Study (DOPPS). Nephrol Dial Transplant 2004;19:108-120.
Goodkin DA, Young EW, Kurokawa K, Prütz KG, Levin NW: Mortality among hemodialysis patients in Europe, Japan, and the United States: case-mix effects. Am J Kidney Dis 2004;44(suppl 2):16-21.
Goodkin DA, Bragg-Gresham JL, Koenig KG, Wolfe RA, Akiba T, Andreucci VE, Saito A, Rayner HC, Kurokawa K, Port FK, Held PJ, Young EW: Association of comorbid conditions and mortality in hemodialysis patients in Europe, Japan, and the United States: the Dialysis Outcomes and Practice Patterns Study (DOPPS). J Am Soc Nephrol 2003; 14:3270-3277. 
-4 Bradbury BD, Fissell RB, Albert JM, Anthony MS, Critchlow CW, Pisoni RL, Port FK, Gillespie BW: Predictors of early mortality among incident US hemodialysis patients in the Dialysis Outcomes and Practice Patterns Study (DOPPS). Clin J Am Soc Nephrol 2007;2:89-99.

5 Portolés J, López-Gómez JM, Gruss E, Aljama P; MAR Study Group: Course of vascular access and relationship with treatment of anemia. Clin J Am Soc Nephrol 2007;2:11631169.

6 Thomson PC, Stirling CM, Geddes CC, Morris ST, Mactier RA: Vascular access in haemodialysis patients: a modifiable risk factor for bacteraemia and death. QJM 2007; 100:415-422.

7 Tordoir J, Canaud B, Haage P, Konner K, Basci A, Fouque D, Kooman J, Martin-Malo A, Pedrini L, Pizzarelli F, Tattersall J, Vennegoor M, Wanner C, ter Wee P, Vanholder R: EBPG on vascular access. Nephrol Dial Transplant 2007;22(Suppl 2):ii88-ii117.

$\checkmark 8$ Sands JJ: Increasing AV fistulae and decreasing dialysis catheters: two aspects of improving patient outcomes. Blood Purif 2007;25: 99-102.

9 Gonsalves CF, Eschelman DJ, Sullivan KL, DuBois N, Bonn J: Incidence of central vein stenosis and occlusion following upper extremity PICC and port placement. Cardiovasc Intervent Radiol 2003;26:123-127.

$\checkmark 10$ Allon M, Lockhart ME, Lilly RZ, Gallichio MH, Young CJ, Barker J, Deierhoi MH, Robbin ML: Effect of preoperative sonographic mapping on vascular access outcomes in hemodialysis patients. Kidney Int 2001;60: 2013-2020.

-11 Konner K, Hulbert-Shearon TE, Roys EC, Port FK: Tailoring the initial vascular access for dialysis patients. Kidney Int 2002;62: 329-338.

-12 Rayner HC, Besarab A, Brown WW, Disney A, Saito A, Pisoni RL: Vascular access results from the Dialysis Outcomes and Practice Patterns Study (DOPPS): performance against Kidney Disease Outcomes Quality Initiative (K/DOQI) Clinical Practice Guidelines. Am J Kidney Dis 2004;44(suppl 2):22-26.

$\checkmark 13$ Lemaire X, Morena M, Leray-Moragués H, Henriet-Viprey D, Chenine L, Defez-Fougeron C, Canaud B: Analysis of risk factors for catheter-related bacteremia in 2000 permanent dual catheters for hemodialysis. Blood Purif 2009;28:21-28.

14 Meeus G, Kuypers DR, Claes K, Evenepoel P, Maes B, Vanrenterghem Y: A prospective, randomized, double-blind crossover study on the use of $5 \%$ citrate lock versus $10 \%$ citrate lock in permanent hemodialysis catheters. Blood Purif 2005;23:101-105.
15 Kritchevsky SB, Braun BI, Kusek L, Wong ES, Solomon SL, Parry MF, Richards CL, Simmons B; Evaluation of Processes and Indicators in Infection Control (EPIC) Study Group: The impact of hospital practice on central venous catheter associated bloodstream infection rates at the patient and unit level: a multicenter study. Am J Med Qual 2008;23:24-38.

16 Jaffer Y, Selby NM, Taal MW, Fluck RJ, McIntyre CW: A meta-analysis of hemodialysis catheter locking solutions in the prevention of catheter-related infection. Am J Kidney Dis 2008;51:233-241.

17 Canaud B, Leray-Moragues H, Garrigues V, Mion C: Permanent twin catheter: a vascular access option of choice for haemodialysis in elderly patients. Nephrol Dial Transplant 1998;13(suppl 7):82-88

18 Gotch FA: Evolution of the single-pool urea kinetic model. Semin Dial 2001;14:252-256.

19 Gotch F: The basic, quantifiable parameter of dialysis prescription is Kt/V urea; treatment time is determined by the ultrafiltration requirement; all three parameters are of equal importance. Blood Purif 2007;25:1826.

20 Locatelli F, Buoncristiani U, Canaud B, Köhler H, Petitclerc T, Zucchelli P: Haemodialysis with on-line monitoring equipment: tools or toys? Nephrol Dial Transplant 2005; 20:22-33.

-21 Eknoyan G, Beck GJ, Cheung AK, Daugirdas JT, Greene T, Kusek JW, Allon M, Bailey J, Delmez JA, Depner TA, Dwyer JT, Levey AS, Levin NW, Milford E, Ornt DB, Rocco MV, Schulman G, Schwab SJ, Teehan BP, Toto R; Hemodialysis (HEMO) Study Group: Effect of dialysis dose and membrane flux in maintenance hemodialysis. N Engl J Med 2002; 347:2010-2019.

-22 Cheung AK, Rocco MV, Yan G, Leypoldt JK, Levin NW, Greene T, Agodoa L, Bailey J, Beck GJ, Clark W, Levey AS, Ornt DB, Schulman G, Schwab S, Teehan B, Eknoyan G: Serum $\beta-2$ microglobulin levels predict mortality in dialysis patients: results of the HEMO study. J Am Soc Nephrol 2006;17: 546-555.

-23 Locatelli F, Martin-Malo A, Hannedouche T, Loureiro A, Papadimitriou M, Wizemann V, Jacobson SH, Czekalski S, Ronco C, Vanholder R; Membrane Permeability Outcome (MPO) Study Group: Effect of membrane permeability on survival of hemodialysis patients. J Am Soc Nephrol 2009;20:645-654.

24 Spalding EM, Chamney PW, Farrington K: Phosphate kinetics during hemodialysis: evidence for biphasic regulation. Kidney Int 2002;61:655-667.

25 Ward RA, Greene T, Hartmann B, Samtleben W: Resistance to intercompartmental mass transfer limits beta2-microglobulin removal by post-dilution hemodiafiltration. Kidney Int 2006;69:1431-1437.
26 Ozkahya M, Ok E, Toz H, Asci G, Duman S, Basci A, Kose T, Dorhout Mees EJ: Longterm survival rates in haemodialysis patients treated with strict volume control. Nephrol Dial Transplant 2006;21:3506-3513.

$>27$ Weinreich T, De los Ríos T, Gauly A, PasslickDeetjen J: Effects of an increase in time vs. frequency on cardiovascular parameters in chronic hemodialysis patients. Clin Nephrol 2006;66:433-439.

28 Ng TG, Johnson DW, Hawley CM: Is it time to revisit residual renal function in haemodialysis? Nephrology 2007;12:209-217.

$\checkmark 29$ Culleton BF, Walsh M, Klarenbach SW, Mortis G, Scott-Douglas N, Quinn RR, Tonelli M, Donnelly S, Friedrich MG, Kumar A, Mahallati H, Hemmelgarn BR, Manns BJ: Effect of frequent nocturnal hemodialysis vs conventional hemodialysis on left ventricular mass and quality of life: a randomized controlled trial. JAMA 2007; 298:1291-1299.

-30 Saran R, Bragg-Gresham JL, Levin NW, Twardowski ZJ, Wizemann V, Saito A, Kimata N, Gillespie BW, Combe C, Bommer J, Akiba T, Mapes DL, Young EW, Port FK: Longer treatment time and slower ultrafiltration in hemodialysis: associations with reduced mortality in the DOPPS. Kidney Int 2006;69:1222-1228.

31 Marshall MR, Byrne BG, Kerr PG, McDonald SP: Associations of hemodialysis dose and session length with mortality risk in Australian and New Zealand patients. Kidney Int 2006;69:1229-1236.

-32 Yashiro M, Kamata T, Segawa H, Murakami T, Kadoya Y, Muso E: How does higher ultrafiltration within the conventional clinical range impact the volume status of hemodialysis patients? Blood Purif 2009;27:253260

33 Rocco MV, Yan G, Heyka RJ, Benz R, Cheung AK; Hemo Study Group: Risk factors for hypertension in chronic hemodialysis patients: baseline data from the HEMO study. Am J Nephrol 2001;21:280-288.

34 Wabel P, Moissl U, Chamney P, Jirka T, Machek P, Ponce P, Taborsky P, Tetta C, Velasco N, Vlasak J, Zaluska W, Wizemann V: Towards improved cardiovascular management: the necessity of combining blood pressure and fluid overload. Nephrol Dial Transplant 2008;23:2965-2971.

35 Katz AM: Heart Failure; in Fozzard HA, et al (eds): The Heart and Cardiovascular System, ed 2. New York, Raven Press, 1992, pp 333353.

-36 Levin A, Singer J, Thompson CR, Ross H, Lewis M: Prevalent left ventricular hypertrophy in the predilaysis population: identifying opportunities for intervention. Am J Kidney Dis 1996;27:347-354. 
37 Mark PB, Johnston N, Groenning BA, Foster JE, Blyth KG, Martin TN, Steedman T, Dargie HJ, Jardine AG: Redefinition of uremic cardiomyopathy by contrast-enhanced cardiac magnetic resonance imaging. Kidney Int 2006;10:1839-1845.

- 38 Chan CT, Floras JS, Miller JA, Richardson RMA, Pierratos A: Regression of left ventricular hypertrophy after conversion to nocturnal hemodialysis. Kidney Int 2002;61:22352239.

-39 Hegstrom RM, Murray JS, Pendras J, Burnell JM, Scribner BH: Hemodialysis in the treatment of chronic uremia. Trans Am Soc Artif Intern Organs 1961;7:136-149.

40 Ozkahya M, Ok E, Toz H, Asci G, Duman S, Basci A, Kose T, Dorhout Mees EJ: Longterm survival rates in haemodialysis patients treated with strict volume control. Nephrol Dial Transplant 2006;21:3506-3543.

41 Ifudu O: The concept of dry weight in maintenance hemodialysis: flaws in clinical application. Int J Artif Organs 1996:19:384386.

\$2 Leypoldt JK, Cheung AK, Delmez JA, Gassman JJ, Levin NW, Lewis JA, Lewis JL, Rocco MV: Relationship between volume status and blood pressure during chronic hemodialysis. Kidney Int 2002;61:266-275.

43 Kooman JP, van der Sande FM, Leunissen KM: Role of sodium and volume in the pathogenesis of hypertension in dialysis patients: reflections on pathophysiological mechanisms. Blood Purif 2004;22:55-59.

-44 Lins LE, Hedenborg G, Jacobson SH, Samuelson K, Tedner B, Zetterholm UB, Ljungqvist O: Blood pressure reduction during hemodialysis correlates to intradialytic changes in plasma volume. Clin Nephrol 1992:37:308-313.

-45 Lucas MF, Quereda C, Teruel JL, Orte L, Marcen R, Ortuno J: Effect of hypertension before beginning dialysis on survival of hemodialysis patients. Am J Kidney Dis 2003; 41:814-821.

46 Sherman RA, Daniel A, Cody RP: The effect of interdialytic weight gain on predialysis blood pressure. Artif Organs 1993:17:770774.

47 Ventura JE, Sposito M: Volume sensitivity of blood pressure in end-stage renal disease. Nephrol Dial Transplant 1997;12:485-491.

48 Dorhout Mees EJ: Cardiovascular Aspects of Dialysis Treatment; The Importance of Volume Control, ed 1. Dordrecht, Kluwer Academic Publishers, 2000.

49 Port F: End-stage renal disease: magnitude of the problem, prognosis of future trends and possible solutions. Kidney Int 1995;50:S3S6.

50 Charra B: Fluid balance, dry weight, and blood pressure in dialysis. Hemodialysis Int 2007;11:21-31.
51 Katzarski KS, Charra B, Laurent G, Lopot F, Divino-Filho JC, Bergstrom J: Multifrequency bioimpedance in assessment of dry weight in haemodialysis. Nephrol Dial Transplant 1996;11(suppl 2):20-23.

52 Lopot F, Nejedly B, Novotna H, Mackova M, Sulkova S: Age-related extracellular to total body water volume ratio $(\mathrm{Ecv} / \mathrm{TBW})$ - can it be used for dry weight determination in dialysis patients? Application of multifrequency bioimpedance measurement. Int J Artif Organs 2002;25; 8:762-769.

53 Wizemann V, Schilling M: Dilemma of assessing volume state - the use and limitations of a clinical score. Nephrol Dial Transplant 1995;10:2114-2117.

54 Chamney PW, Kraemer M, Rode C, Kleinekofort W, Wizemann V: A new technique for establishing dry weight in hemodialysis patients via whole body bioimpedance. Kidney Int 2002;61:2250-2258.

55 Chamney PW, Wabel P, Moissl UM, Muller MJ, Bosy-Westphal A, Korth O, Fuller NJ: A whole-body model to distinguish excess fluid from the hydration of major body tissues. Am J Clin Nutr 2007;85:1:80-89.

56 Kraemer M, Rode C, Wizemann V: Detection limit of methods to assess fluid status changes in dialysis patients. Kidney Int 2006;69:1609-1620.

57 Wabel P, Chamney P, Moissl U, Jirka T: Importance of whole-body bioimpedance spectroscopy for the management of fluid balance. Blood Purif 2009;1:75-80.

58 Wizemann V, Wabel P, Chamney P, Zaluska W, Moissl U, Rode C, Malecka-Masalska T, Marcelli D: The mortality risk of overhydration in haemodialysis patients. Nephrol Dial Transplant 2009;24:5:1574-1579.

59 Machek P, Jirka T, Chamney P, Moissl U, Wabel P: Guided optimisation of fluid status in haemodialysis patients. Nephrol Dial Transplant 2010;25:538-544.

60 Vanholder R, De Smet R, Glorieux G, Argilés A, Baurmeister U, Brunet P, Clark W, Cohen G, De Deyn PP, Deppisch R, Descamps-Latscha B, Henle T, Jörres A, Lemke HD, Massy ZA, Passlick-Deetjen J, Rodriguez M, Stegmayr B, Stenvinkel P, Tetta C, Wanner C, Zidek W; European Uremic Toxin Work Group (EUTox): Review on uremic toxins: classification, concentration, and interindividual variability. Kidney Int 2003;63:19341943.

61 Vanholder R, Baurmeister U, Brunet P, Cohen G, Glorieux G, Jankowski J; European Uremic Toxin Work Group: A bench to bedside view of uremic toxins. J Am Soc Nephrol 2008;19:863-870.

62 Young EW, Albert JM, Satayathum S, Goodkin DA, Pisoni RL, Akiba T, Akizawa T, Kurokawa K, Bommer J, Piera L, Port FK: Predictors and consequences of altered mineral metabolism: the Dialysis Outcomes and Practice Patterns Study. Kidney Int 2005;67: 1179-1187.
63 Cheung AK, Rocco MV, Yan G, Leypoldt JK, Levin NW, Greene T, Agodoa L, Bailey J, Beck GJ, Clark W, Levey AS, Ornt DB, Schulman G, Schwab S, Teehan B, Eknoyan G: Serum $\beta-2$ microglobulin levels predict mortality in dialysis patients: results of the HEMO study. J Am Soc Nephrol 2006;17: 546-555.

64 Cheung AK, Greene T, Leypoldt JK, Yan G, Allon M, Delmez J, Levey AS, Levin NW, Rocco MV, Schulman G, Eknoyan G; HEMO Study Group: Association between serum 2-microglobulin level and infectious mortality in hemodialysis patients. Clin J Am Soc Nephrol 2008;3:69-77.

-65 Canaud B, Morena M, Cristol JP, Krieter D: $\beta 2$-Microglobulin, a uremic toxin with a double meaning. Kidney Int 2006;69:12971299.

-66 Bammens B, Evenepoel P, Keuleers H, Verbeke K, Vanrenterghem Y: Free serum concentrations of the protein-bound retention solute p-cresol predict mortality in hemodialysis patients. Kidney Int 2006;69:10811087.

-67 Chauveau P, Nguyen H, Combe C, Chêne G, Azar R, Cano N, Canaud B, Fouque D, Laville M, Leverve X, Roth $\mathrm{H}$, Aparicio M; French Study Group for Nutrition in Dialysis: Dialyzer membrane permeability and survival in hemodialysis patients. Am J Kidney Dis 2005;45:565-571.

-68 Krane V, Krieter DH, Olschewski M, März W, Mann JF, Ritz E, Wanner C: Dialyzer membrane characteristics and outcome of patients with type 2 diabetes on maintenance hemodialysis. Am J Kidney Dis 2007; 49:267-275.

69 Cheung AK, Levin NW, Greene T, Agodoa L, Bailey J, Beck G, Clark W, Levey AS, Leypoldt JK, Ornt DB, Rocco MV, Schulman G, Schwab S, Teehan B, Eknoyan G: Effects of high-flux hemodialysis on clinical outcomes: results of the HEMO study. J Am Soc Nephrol 2003; 14:3251-3263.

70 Canaud B, Bragg-Gresham JL, Marshall MR, Desmeules S, Gillespie BW, Depner T, Klassen P, Port FK: Mortality risk for patients receiving hemodiafiltration versus hemodialysis: European results from the DOPPS. Kidney Int 2006;69:2087-2093.

-71 Panichi V, Rizza GM, Paoletti S, Bigazzi R, Aloisi M, Barsotti G, Rindi P, Donati G, Antonelli A, Panicucci E, Tripepi G, Tetta C, Palla R; RISCAVID Study Group: Chronic inflammation and mortality in haemodialysis: effect of different renal replacement therapies - results from the RISCAVID study. Nephrol Dial Transplant 2008;23:23372343.

72 Canaud B, Morena M, Leray-Moragues H, Chalabi L, Cristol JP: Overview of clinical studies in hemodiafiltration: what do we need now? Hemodial Int 2006;10(suppl 1): S5-S12. 
73 Vanholder R, Eloot S, Van Biesen W: Do we need new indicators of dialysis adequacy based on middle-molecule removal? Nat Clin Pract Nephrol 2008;4:174-175.

74 Ward RA: Ultrapure dialysate: a desirable and achievable goal for routine hemodialysis. Semin Dial 2000;13:378-380.

-75 Penne EL, Visser L, van den Dorpel MA, van der Weerd NC, Mazairac AH, van Jaarsveld BC, Koopman MG, Vos P, Feith GW, Kremer Hovinga TK, van Hamersvelt HW, Wauters IM, Bots ML, Nubé MJ, Ter Wee PM, Blankestijn PJ, Grooteman MP: Microbiological quality and quality control of purified water and ultrapure dialysis fluids for online hemodiafiltration in routine clinical practice. Kidney Int 2009;76:665-672.
76 Canaud BJ: Changing paradigms of renal replacement therapy in chronic kidney disease patients: ultrapure dialysis fluid and highefficiency hemodiafiltration for all? Kidney Int 2009;76:591-593.

77 Tetta C, David S, Marcelli D, Cogliati P, Formica $\mathrm{M}$, Inguaggiato $\mathrm{P}$, Panichi V: Clinical effects of online dialysate and infusion fluids. Hemodial Int 2006;10(suppl 1):S60-S66.
78 Lederer SR, Schiffl H: Ultrapure dialysis fluid lowers the cardiovascular morbidity in patients on maintenance hemodialysis by reducing continuous microinflammation. Nephron 2002;91:452-455.

79 Port FK, Pisoni RL, Bragg-Gresham JL, Satayathum SS, Young EW, Wolfe RA, Held PJ: DOPPS estimates of patient life years attributable to modifiable hemodialysis practices in the United States. Blood Purif 2004;22: 175-180.

-80 Alquist M, Bosch JP: Treatment mapping: a systematic methodology to assess quality, efficiency and variability in the hemodialysis delivery process. Blood Purif 2008;26:417422 . 